\title{
Hemodynamic and metabolic changes prior to speech performance
}

\author{
JEFFREY A. GLINER, DAVID E. BUNNELL, and STEVEN M. HORVATH \\ Institute of Environmental Stress, University of California, Santa Barbara, California
}

\begin{abstract}
Cardiovascular and metabolic responses were recorded from 12 subjects immediately prior to an oral presentation and during a control period when others were giving this presentation. Cardiac output, blood pressure, oxygen consumption, and other hemodynamic and metabolic responses were measured in order to determine whether the cardiovascular responses during anxiety were in exaggeration of the metabolic demands of the situation. Although there were wide individual differences among subjects, definite relationships emerged. A significant negative correlation between change in cardiac output and change in arterial-venous difference during anxiety demonstrated that a cardiovascular-metabolic dissociation had taken place as a function of anxiety. Furthermore, a significant negative correlation between change in cardiac output and change in total peripheral resistance during anxiety suggested that increased epinephrine was probably mediating the cardiovascular change. There was no one representative hemodynamic pattern due to the preperformance anxiety, indicating the necessity of assessing overall hemodynamic response patterning in subjects when attempting to characterize cardiovascular-metabolic responses to psychological stress.
\end{abstract}

There is a close relationship between cardiovascular and somatic activity during most free-movement situations (Obrist, Howard, Lawler, Galosy, Meyers, \& Gaebelein, 1974). However, large increases in heart rate may occur independently of equivalent increases in somatic activity (e.g., Bernard \& Duncan, 1975; Imhof, Blatter, Fuccella, \& Turri, 1969; McCafferty, Gliner, \& Horvath, 1978; Taggert, Carruthers, \& Somerville, 1973); such dissociations seem to occur primarily in stressful environments (Obrist, 1976).

Recently, attempts have been made to more completely assess the hemodynamic response pattern accompanying cardiac-somatic dissociation. Thus, Gliner, Bedi, and Horvath (1979) demonstrated that heart rate (HR) acceleration in an anxiety situation is accompanied by an increased cardiac output (CO) with minimal change in stroke volume. This increased cardiac output during anxiety was equivalent to that found during light exercise at similar HRs, suggesting that the hemodynamic response to emotional stress was in excess of the metabolic demands of the situation. Unfortunately, metabolic demands were not directly assessed in the Gliner et al. (1979) study. Langer, Obrist, and McCubbin (1979) did assess in

This work was supported in part by Environmental Protection Agency Grant EPA R808177010 and Air Force Office of Scientific Research, Air Force Systems Command Grant AFOSR 78-3534. Please address requests for reprints and correspondence to: Jeffrey A. Gliner, who is now with the Department of Occupational Therapy, Colorado State University, Fort Collins, Colorado 80523.

-Article accepted by previous editor, Richard F. Thompson. dogs the metabolic demands of a shock avoidance situation, indirectly, by measuring both cardiac output and arterial-venous oxygen $\left(\mathrm{A}-\mathrm{V}_{\mathrm{O}_{2}}\right)$ difference. In their study, estimated oxygen uptakes during shock avoidance were significantly less than those observed during a more relevant metabolic stress, exercise; however, cardiac output in the two different situations was equivalent. The lower $\mathrm{O}_{2}$ consumption indicated by the smaller $\mathrm{A}-\mathrm{V}_{\mathrm{O}_{2}}$ difference during shock avoidance resulted in a state of overperfusion. Additionally, arterial pressures were significantly elevated relative to those observed in exercise. Interestingly, however, $\mathrm{O}_{2}$ uptakes in Langer et al.'s (1979) dogs during shock avoidance were $150 \%$ above resting levels, suggesting that some degree of somatic activity was present in that condition. This, in turn, may have affected the reported pattern of hemodynamic responding.

The purpose of the present study was to extend the findings of both these studies through: (1) expanding the number of cardiovascular and metabolic parameters assessed concomitantly in one situation, and (2) use of a stressor which appeared to produce a situation of cardiac-somatic dissociation in human subjects in the Gliner et al. (1979) study. Resting hemodynamic and metabolic response patterns were determined as subjects anticipated a subjectively stressful task: presenting a talk before an audience. Correlations between simultaneous measures of HR, stroke volume, cardiac output, systolic and diastolic blood pressure (SBP, DBP), total peripheral resistance (TPR), and systolic preejection period (PEP) were determined along with ventilation volume $\left(V_{E}\right)$ and 
$\mathrm{O}_{2}$ uptake to delineate cardiac-metabolic relationships under emotional stress.

In contrast to the above approach, which focused on the description of a characteristic cardiovascularsomatic response pattern during emotional stress, individual differences in cardiovascular response patterning were also considered. This approach was suggested by earlier reports of divergent cardiovascular response patterns observed in response to speaking before an audience (Taggart et al., 1973) and in response to stresses such as examinations (e.g., Hickam, Cargill, \& Golden, 1948). Also of interest in this regard were response patterns in individuals displaying high HR reactivity, since this measure has been used recently to characterize subjects with exaggerated cardiovascular responses to stressors (e.g., Manuck \& Garland, 1980; Bunnell, Note 1; Hastrup, Light, \& Obrist, Note 2).

\section{METHOD}

\section{Subjects}

Thirteen subjects ${ }^{1}$ (10 females and 3 males), between the ages of 20 and 24 years, volunteered for this study. All subjects selected were from the same course in perception and motor learning. One female subject was present only for the experimental session, and was therefore eliminated from the study.

\section{Apparatus}

Stroke volume was measured by an IFM/Minnesota impedance cardiograph. Thoracic impedance to a 4-mA, constant current $100-\mathrm{kHz}$ signal was measured through the cardiograph. For both a description and general review of this method, see Miller and Horvath (1978).

Heart rate (ECG) and the first derivative of pulsatile thoracic impedance $(\mathrm{dz} / \mathrm{dt})$ were recorded on a Sanborn recorder. Cardiac output was calculated by the formula heart rate $(\mathrm{HR}) \times$ stroke volume (SV). Blood pressure was determined by the Riva-Rocci method. Preejection period (PEP) was measured from the peak of the $R$ wave to the baseline crossing of $\mathrm{dz} / \mathrm{dt}$ in systole (Siegel, Fabian, Lankau, Cole, Nahmad, \& Levine, Note 3). Paper speed was $50 \mathrm{~mm} / \mathrm{sec}$ to allow visual scoring of the $\mathrm{dz} / \mathrm{dt}$ trace. Ventilatory volumes were measured by collecting the expired gas in a 120-liter Collins spirometer. Aliquot samples of the collected gas were analyzed for oxygen and carbon dioxide, using a Quintron gas chromatograph calibrated against Haldane analyzed gases.

\section{Procedure}

Each subject participated on two occasions, once immediately prior to giving a 15-min presentation and once prior to a time when others would be giving this presentation. The presentation involved a demonstration of how to teach a particular perceptualmotor task. This demonstration was $10 \%$ of the students' total grade for the class. The monitoring sessions lasted $15 \mathrm{~min}$, but measurements were recorded only during the last $10 \mathrm{~min}$. Both conditions were conducted on different days, spaced 1 week apart and counterbalanced to control for any order effects. Immediately before each session, the subject responded to a short form of the Spielberger State Anxiety Scale. This consisted of four items from the 20-item STAI A-State scale (Spielberger, Gorsuch, Lushene, 1970). These four items were: (a) "I feel pleasant," (b) "I feel regretful," (c) "I find myself worrying about something," and (d) "I am calm." Each subject rated each item on a 4-point scale, with 1 being "not at all" to 4 being "very much so." These four items had shown the highest item-remainder correlation coefficients in previous research (Spielberger \& Gorsuch, Note 4) and had been used successfully by O'Neill, Spielberger, and Hansen (1969). The subjects' instructions during the recording period were simply to relax.

The subject was prepared with Mylar $^{2}$ tape electrodes around the neck and abdomen for thoracic impedance measurements 15 min prior to each treatment condition. After the electrodes were in place, the subject inserted a "Y"-valve mouthpiece into the mouth for recording metabolic data and a nose clip was placed over the nose to restrict nasal breathing. The blood pressure cuff was applied at this time. All subjects were seated in an upright posture during each treatment condition.

\section{Data Quantification and Analysis}

The subjects were monitored for 10 min during each treatment condition. Stroke volume measurements were performed at the beginning of the 10-min period, between Minutes 4 and 5 and between Minutes 9 and 10 . Within each recording segment, two measurements were sampled and averaged together, thus yielding a measure of HR, SV, PEP, and CO for each of the three different segments. Systolic and diastolic blood pressures were recorded twice during the first minute and twice during the last minute of the 10-min session. Thus, for the first and last segments, mean

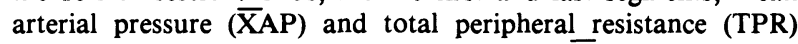
could be determined; TPR was computed as XAP/CO and was expressed in $\mathrm{mmHg} /(\mathrm{ml} / \mathrm{min})$. Oxygen uptake and ventilation were sampled during the entire 10 -min period; $\mathrm{A}-\mathrm{V}_{\mathrm{O}_{2}}$ difference was computed from this data as $\mathrm{O}_{2}$ uptake/CO and expressed as volume $\%$. Complete metabolic and hemodynamic measures were therefore available only for the last segment.

In order to assess stress-induced changes from the hemodynamic measures, a three-factor mixed analysis of variance was performed. The between-groups factor was the order of treatment conditions. This was included because it was anticipated that the relatively large number of physiological transducers used, and the unfamiliarity of the subjects with these transducers might increase stress on a first-time basis. This could obscure any treatment effects. The within-subject factors were the stress condition (talk presentation) and time within this condition. Metabolic data, which yielded only one measure per $10-\mathrm{min}$ period, were analyzed by paired $t$ tests, as were the four questions from the anxiety questionnaire. Pearson product-moment correlations were applied to determine the relationship between changes in individual hemodynamic and metabolic parameters due to the anxiety condition. Factor analysis was also applied to the obtained correlation matrix to aid in characterizing response patterning during anxiety. The significance level adopted for all statistical tests was .05, two-tailed.

\section{RESULTS}

\section{Self-Report Data}

Analysis of the anxiety questionnaire demonstrated that the subjects were more anxious during the preperformance condition. Significantly higher scores were observed for the items "more regretful" $[\mathrm{t}(11)=2.52, \mathrm{p}<.05]$, "less pleasant" $[\mathrm{t}(11)=2.62$, $\mathrm{p}<.05]$, and "more worrisome" $[\mathrm{t}(11)=2.70, \mathrm{p}<.05]$ in the anxiety condition.

\section{Physiological Responses}

Table 1 presents the hemodynamic and metabolic changes during the control and anxiety conditions for each of the 12 subjects during the third (last) recording period. Metabolic data for Subject 12 was lost. There was considerable variability between subjects. Some individuals displayed relatively large increases in $\mathrm{HR}$ and $\mathrm{CO}$ during the anxiety condition, while 
Table 1

Individual Hemodynamic and Metabolic Responses During Baseline and Anxiety Periods

\begin{tabular}{|c|c|c|c|c|c|c|c|c|c|c|c|}
\hline & $\mathrm{HR}$ & SV & $\mathrm{CO}$ & SBP & DBP & $\overline{\mathrm{X}} \mathrm{AP}$ & TPR & $\mathrm{V}_{\mathrm{E}}$ & $\mathrm{O}_{2}$ & $\mathrm{~A}-\mathrm{V}_{\mathrm{O}_{2}}$ & PEP \\
\hline & & & & & & Subject 1 & & & & & \\
\hline Baseline & 68 & 82 & 5.6 & 118 & 82 & 94 & .016 & 7.13 & 260 & 4.6 & 95 \\
\hline \multirow[t]{2}{*}{ Anxiety } & 90 & 92 & 8.3 & 142 & 75 & 97 & .012 & 7.15 & 296 & 3.6 & 60 \\
\hline & & & & & & Subject 2 & & & & & \\
\hline Baseline & 68 & 101 & 6.9 & 108 & 70. & 83 & .012 & 6.99 & 264 & 3.8 & 78 \\
\hline \multirow[t]{2}{*}{ Anxiety } & 86 & 66 & 5.7 & 124 & 70 & 88 & .015 & 6.25 & 249 & 4.4 & 75 \\
\hline & & & & & & Subject 3 & & & & & \\
\hline Baseline & 63 & 98 & 6.8 & 78 & 65 & 69 & .010 & 6.72 & 249 & 3.7 & 108 \\
\hline \multirow[t]{2}{*}{ Anxiety } & 74 & 82 & 6.0 & 90 & 60 & 70 & .012 & 5.47 & 220 & 3.6 & 90 \\
\hline & & & & & & Subject 4 & & & & & \\
\hline Baseline & 73 & 58 & 4.2 & 104 & 75 & 85 & .020 & 5.28 & 190 & 4.5 & 120 \\
\hline \multirow[t]{2}{*}{ Anxiety } & 63 & 59 & 3.7 & 99 & 68 & 78 & .021 & 7.87 & 242 & 6.5 & 124 \\
\hline & & & & & & Subject 5 & & & & & \\
\hline Baseline & 89 & 77 & 6.8 & 120 & 90 & 100 & .015 & 5.30 & 244 & 3.6 & 62 \\
\hline \multirow[t]{2}{*}{ Anxiety } & 100 & 64 & 6.4 & 110 & 84 & 93 & .015 & 7.64 & 270 & 4.2 & 70 \\
\hline & & & & & & Subject 6 & & & & & \\
\hline Baseline & 68 & 57 & 3.9 & 98 & 80 & 86 & .022 & 4.92 & 240 & 6.2 & 88 \\
\hline \multirow[t]{2}{*}{ Anxiety } & 89 & 59 & 5.2 & 118 & 68 & 85 & .016 & 5.14 & 213 & 4.1 & 87 \\
\hline & & & & & & Subject 7 & & & & & \\
\hline Baseline & 55 & 92 & 5.1 & 112 & 88 & 96 & .019 & 8.32 & 265 & 5.2 & 88 \\
\hline \multirow[t]{2}{*}{ Anxiety } & 72 & 108 & 7.8 & 102 & 80 & 87 & .011 & 9.91 & 324 & 4.2 & 71 \\
\hline & & & & & & Subject 8 & & & & & \\
\hline Baseline & 78 & 67 & 5.2 & 110 & 98 & 102 & .020 & 5.96 & 245 & 4.7 & 109 \\
\hline \multirow[t]{2}{*}{ Anxiety } & 83 & 63 & 5.2 & 102 & 78 & 86 & .017 & 5.92 & 210 & 4.0 & 93 \\
\hline & & & & & & Subject 9 & & & & & \\
\hline Baseline & 50 & 63 & 3.2 & 118 & 85 & 96 & .030 & 5.34 & 242 & 7.5 & 93 \\
\hline \multirow[t]{2}{*}{ Anxiety } & 61 & 90 & 5.2 & 108 & 78 & 88 & .017 & 6.32 & 270 & 5.1 & 94 \\
\hline & & & & & & Subject 10 & & & & & \\
\hline Baseline & 88 & 62 & 5.5 & 122 & 90 & 101 & .018 & 9.22 & 361 & 6.6 & 88 \\
\hline \multirow[t]{2}{*}{ Anxiety } & 74 & 76 & 5.6 & 154 & 90 & 111 & .020 & 9.30 & 358 & 6.4 & 80 \\
\hline & & & & & & Subject 11 & & & & & \\
\hline Baseline & 85 & 100 & 8.5 & 117 & 78 & 91 & .011 & 7.18 & 313 & 3.7 & 106 \\
\hline \multirow[t]{2}{*}{ Anxiety } & 61 & 104 & 6.3 & 136 & 80 & 99 & .016 & 6.82 & 344 & 5.5 & 89 \\
\hline & & & & & & Subject 12 & & & & & \\
\hline Baseline & 61 & 71 & 4.3 & 120 & 90 & 100 & .023 & & & & 87 \\
\hline Anxiety & 79 & 76 & 6.0 & 122 & 90 & 101 & .017 & & & & 79 \\
\hline
\end{tabular}

Note-Cardiovascular data are from the third sampling period. $V_{E}$ and $O_{2}$ reflect the entire 10-min recording period. HR $=$ heart rate (in beats per minute); $S V=$ stroke volume (in milliliters per beat); $C O=$ cardiac output (in liters per minute); $S B P=$ systolic . blood pressure , $D B P=$ diastolic blood pressure, and $\bar{X} A P=$ mean arterial pressure (all in millimeters of mercury); TPR $=$ total peripheral resistance (in millimeters of mercury/milliliters per minute); $V_{E}=$ ventilation (in liters per minute BTPS); $O_{2}=$ oxygen uptake (in milliliters per minute STPD); $A \cdot V_{\mathrm{O}_{2}}=$ arterial-venous oxygen difference (in percent); $P E P=$ preejection period (in milliseconds).

three subjects actually had values lower than those observed in control conditions.

For the group as a whole, however, ANOVAs and $t$ tests revealed no significant main effects for increases in any of the physiological indices due to the anxiety condition, although $\mathrm{HR}[\mathrm{F}(1,10)=3.87$, $\mathrm{p}=.078]$ and cardiac output $[\mathrm{F}(1,10)=2.86, \mathrm{p}=.12]$ approached significance. Stroke volume showed a significant decrease $[\mathrm{F}(2,20)=3.81, \mathrm{p}<.05]$ over the course of the 10-min recording session. A significant stress $\times$ time interaction $[F(1,10)=4.81$, $\mathrm{p}<.05]$ demonstrated a small increase in diastolic pressure over time during the stress session as compared with a small decrease in diastolic pressure over time during the control session. There was a positive, but nonsignificant, relationship $[\mathrm{r}(10)=.40]$ between the ordinal position of presentation and heart rate change.

The major focus of this experiment was to describe the relationships among hemodynamic and metabolic variables as a function of anxiety. Therefore, a percentage change score was computed between control 
Table 2

Between-Subjects Correlations Among Hemodynamic and Metabolic Changes

\begin{tabular}{|c|c|c|c|c|c|c|c|c|c|c|c|}
\hline & HR & SV & PEP & $\mathrm{CO}$ & SBP & DBP & $\overline{\mathrm{X}} \mathrm{AP}$ & TPR & $\mathrm{V}_{\mathrm{E}}$ & $\mathrm{O}_{2}$ & $\mathrm{~A}-\mathrm{V}_{\mathrm{O}_{2}}$ \\
\hline HR & 1.000 & & & & & & & & & & \\
\hline SV & .078 & 1.000 & & & & & & & & & \\
\hline PEP & -.063 & -.161 & 1.000 & & & & & & & & \\
\hline $\mathrm{CO}$ & .793 & .540 & -.243 & 1.000 & & & & & & & \\
\hline SBP & -.180 & -.093 & -.347 & -.324 & 1.000 & & & & & & \\
\hline DBP & -.379 & -.053 & .047 & -.398 & .423 & 1.000 & & & & & \\
\hline XAP & -.366 & -.126 & -.100 & -.483 & .835 & .819 & 1.000 & & & & \\
\hline TPR & -.742 & -.573 & .078 & -.892 & .434 & .639 & .668 & 1.000 & & & \\
\hline $\mathrm{V}_{\mathrm{E}}$ & .073 & .187 & .575 & .128 & -.672 & -.158 & -.523 & -.305 & 1.000 & & \\
\hline $\mathrm{O}$ & .009 & .366 & -.068 & .260 & -.667 & -.152 & -.583 & -.316 & .681 & 1.000 & \\
\hline $\mathrm{A}-\mathrm{V}_{\mathrm{O}_{2}}$ & -.683 & -.425 & .244 & -.735 & -.007 & .550 & .315 & .806 & .238 & .237 & 1.000 \\
\hline
\end{tabular}

Note-Correlations are computed on change scores, expressed as percentage change from the control condition. $n=11$ for all correlations. If $|r|>.60, p<.05$.

and anxiety conditions for each subject for each physiological variables. A correlation matrix computed from these data is presented in Table 2 . Heart rate and stroke volume correlated significantly with changes in cardiac output. However, the changes in cardiac output were not significantly related to changes in any of the blood pressure measures (SBP, DBP, and $\overline{X A P)}$ primarily due to the highly significant negative correlation $[\mathrm{r}(10)=-.89, \mathrm{p}<.01]$ between changes in cardiac output and changes in peripheral resistance. Preejection period (PEP), a measure said to reflect cardiac contractility (e.g., Ahmed, Levinson, Schwartz, \& Ettinger, 1972), did not correlate significantly with any of the hemodynamic measures. As anticipated, changes in oxygen uptake due to anxiety correlated significantly with changes in ventilation. However, the most important relationship was that between cardiac output and oxygen uptake, which from our viewpoint would be the best index of the cardiac-somatic relationship. The low positive correlation of .26 between the changes in these variables revealed a dissociation under anxiety conditions. This dissociation was further evidenced by the significant negative correlation between cardiac output and $\mathrm{A}-\mathrm{V}_{\mathrm{O}_{2}}$ difference $[\mathrm{r}(10)=-.74, \mathrm{p}<.01]$.

Cardiovascular and metabolic response patterning was further elucidated by a factor analysis (orthogonal rotation method) of the correlation matrix presented in Table 2. This yielded a primary factor in which increases of HR and $\mathrm{CO}$ were coupled with decreases in $\mathrm{A}-\mathrm{V}_{\mathrm{O}_{2}}$ difference and TPR; all four variables had factor loadings greater than an absolute value of .81. Furthermore, SBP loaded insignificantly on this factor.

Examination of individual response patterns in Table 1 revealed some interesting trends regarding HR and SBP reactivity. Nine of the 12 subjects responded to the anxiety condition with an increase in $\mathrm{HR}$, and 5 of the 9 had increases greater than $15 \mathrm{bpm}$. Four of these more reactive subjects displayed significant increases in cardiac output, while the fifth showed a decline. Of the remaining four subjects who showed HR increases (11 bpm or less), three showed no change or a drop in CO and one showed a substantial increase. Thus, in general, the subjects displaying the greatest $\mathrm{HR}$ reactivity also displayed substantial increases in cardiac output. However, these subjects failed to show a parallel increase in $\mathrm{O}_{2}$ uptake, consistent with a dissociation of the normal cardiac-metabolic relationship.

By contrast, HR reactivity and SBP reactivity did not covary except in the two largest $H R$ reactors (No. 1 and No. 6). Thus, while all those who substantially increased $\mathrm{CO}$ showed a parallel drop in TPR, not all showed increases in SBP. Two subjects with increased cardiac output (No. 7 and No. 12) showed a drop or no change in SBP. Also, two subjects whose HR decreased relative to baseline (No. 10 and No. 11) showed large increases in SBP; this was apparently due to an increased TPR during anxiety.

\section{DISCUSSION}

The present study sought to delineate cardiovascular and metabolic relationships in an anxiety state. Although self-report data indicated a reliable subjective response to the anxiety manipulation, physiological responses varied markedly. This lack of psychological and physiological parallelism was difficult to explain. For example, the three subjects who showed a decline in HR in the anxiety condition were no less anxious in that condition than other subjects. Although the inexperience with physiological transducers might have contributed somewhat to the wide variability among physiological indices, failure to find a significant interaction effect between treatment and order ruled this out as a major explanation. An alternative explanation was the probability that subjects' anxiety level decreased as others, preceding them in presentation, demonstrated that the task was less anxiety provoking than anticipated. There was a positive relationship observed between the amount 
of heart rate change and rank order of presentation. Although this does not explain the differences in subjective anxiety between the treatment and control conditions, there were obvious demand characteristics associated with the task. It may also be noted that this effect was not observed in a previous study (Gliner et al., 1979), in which subjects had greater familiarity with physiological recording techniques and the impending speaking task was longer and of greater personal importance.

Despite these variable responses, some consistent relationships which provide insight into the cardiovascular-metabolic relationship during anxiety emerged. These relationships were consistent even in those subjects who were apparently more anxious in the control condition. Thus, the nonsignificant relationship between increases in cardiac output and changes in oxygen uptake demonstrated that, at least for this situation, a dissociation was produced between cardiac and metabolic variables. This supported the animal study by Langer et al. (1979) which found the $\mathrm{A}-\mathrm{V}_{\mathrm{O}_{2}}$ difference to be less during anxiety than during exercise at equivalent cardiac output. When cardiac output did increase during anxiety, it suggested that neural control superceded the metabolic demands of the situation.

In contrast to Langer et al. (1979), who observed cardiovascular-metabolic dissociation in conjunction with acute pressor responses, the present study found no correlations between measures of arterial pressure and cardiac output. Instead, change in TPR showed a highly significant negative correlation with cardiac output, tending to hold down large increases in arterial pressure. Such a pattern is consistent with reports indicating a twofold elevation of plasma epinephrine levels associated with public speaking (Dimsdale \& Moss, 1980). Thus, the decreased peripheral resistance may reflect vasodilatory actions of epinephrine on beta $_{2}$ receptors in skeletal muscle. The vasodilator effect of epinephrine ${ }^{3}$ typically dominates the circulatory pattern, and any rise in systolic pressure is predominantly due to an increased cardiac output (Innes \& Nickerson, 1975). Thus, the effect on the vasculature is likely independent of cardiac effects induced by centrally mediated sympathetic outflow. Moreover, depending on the ratio of alpha to beta response in various vascular beds (and depending on epinephrine levels), a slight rise in TPR may occur, as was observed in some subjects. This, in turn, was associated with an increase in SBP.

The cardiovascular responses in the present study were not homogeneous. They are best characterized by an increase in cardiac output, primarily by increases in HR. Increased contractility, as indexed by PEP, seemed to have no major role in effecting these changes in cardiac output, except in the most reactive subjects. Activation of the adrenomedullary system acted primarily on the vasculature. The decrease in
TPR acted to compensate for increases in cardiac output, and arterial pressure remained fairly constant; in some individuals, however, the increase in cardiac output was sufficient to induce a significant increase in SBP. Finally, because there were minimal metabolic demands, the increased cardiac output resulted in a decreased $\mathrm{A}-\mathrm{V}_{\mathrm{O}_{2}}$ difference from the control condition.

Beyond these basic relationships, there was no representative response pattern. Regarding HR reactivity, high reactors tended to increase cardiac output as well, although there were exceptions. Moreover, increased cardiac output was not consistently related to blood pressure increases as previously proposed (Gliner et al., 1979). When blood pressure increases with HR, it is likely a function of both the magnitude of cardiac output increase and the extent of adrenergic alteration on peripheral resistance. In this respect, assessment of catecholamines might have provided some insight into the idiosyncratic cardiovascular responses observed here. Nevertheless, this response variability indicated the value of assessing overall hemodynamic response patterning prior to formulating theories concerning the cardiovascularmetabolic response to psychological stressors.

\section{REFERENCE NOTES}

1. Bunnell, D. E. Effects of autonomic and stimulus factors on the reproducibility of heart rate reactivity. Paper presented at the 20th annual meeting of the Society for Psychophysiological Research, Vancouver, 1980.

2. Hastrup, J. L., Light, K. C., \& Obrist, P. A. Relationship of cardiovascular stress response to parental history of hypertension and to sex differences. Paper presented at the 1979 meeting of the Society for Psychophysiological Research, Cincinnati, 1979.

3. Siegel, J. H., Fabian, M., Lankau, C., Cole, A., Nahmad, M., \& Levine, M. Clinical and experimental use of thoracic impedance plethysmography in quantifying myocardial contractility. In W. G. Kubicek, D. A. Witsoe, R. P. Patterson, \& A. H. L. From (Eds.), Development and evaluation of an impedance cardiographic system to measure cardiac output and other cardiac parameters (NASA-CR-101965; also N70-10008). Houston: National Aeronautics and Space Administration, 1969.

4. Spielberger, C. D., \& Gorsuch, R. L. Mediating processes in verbal conditioning. Final report to United States Public Health Service for Grants MH 7229, MH 7446, and HD 947.

\section{REFERENCES}

Ahmed, S. S., Levinson, G. E., Schwartz, C. J., \& Ettinger, $P$. O. Systolic time intervals as measures of the contractile state of the left ventricular myocardium in man. Circulation, 1972, 46, 559-571.

BERNARD, R., \& DunCAN, H. Heart rate and ECG responses of fire fighters. Journal of Occupational Medicine, 1975, 17, 247-250.

Dimsdale, J. E., \& Moss, J. Plasma catecholamines in stress and exercise. Journal of the American Medical Association, $1980,243,340-342$.

Gliner, J. A., Bedi, J. F., \& Horvath, S. M. Somatic and nonsomatic influences on the heart: Hemodynamic changes. Psychophysiology, 1979, 16, 358-362.

Hickam, J. B., Cargill, W. H., \& Golden, A. Cardiovascular 
reactions to emotional stimuli: Effect on the cardiac output, arteriovenous oxygen difference, arterial pressure, and peripheral resistance. Journal of Clinical Investigation, 1948, 27, 290-298.

Imhof, P. R., Blatter, K., Fuccella, L. M., \& Turri, M. Beta-blockade and emotional tachycardia; radiotelemetric investigations in ski jumpers. Journal of Applied Psychology, 1969, 27, 366-369.

InNes, I. R., \& Nickerson, M. Norepinephrine, epinephrine, and the sympathomimetic amines. In L. S. Goodman \& A. Golman (Eds.), The pharmacological basis of therapeutics. New York: Macmillan, 1975.

Langer, A. W., Obrist, P. A., \& McCubbin, J. A. Hemodynamic and metabolic adjustments during exercise and shock avoidance in dogs. American Journal of Physiology, 1979, 236, H225-H230.

Manuck, S. B., \& Garland, F. N. Stability of individual differences in cardiovascular reactivity: A thirteen month follow-up. Physiology \& Behavior, 1980, 24, 621-624.

McCafferty, W. B., Gliner, J. A., \& Horvath, S. M. The stress of coaching. The Physician and Sportsmedicine, 1978, 6, 67-71.

Mille R, J. C., \& Horvath, S. M. Impedance cardiography. Psychophysiology, 1978, 15, 80-91.

OвRIST, P. A. The cardiovascular-behavioral interaction-as it appears today. Psychophysiology, 1976, 13, 95-107.

Obrist, P. A., Howard, J. L., Lawler, J. E., Galosy, R. A., Meyers, K. A., \& Gaebelein, C. J. The cardiac-somatic interaction. In P. A. Obrist, A. H. Black, J. Brener, \& L. V. DiCara (Eds.), Cardiovascular psychophysiology. Chicago: Aldine, 1974.

O’Neill, H. F., Spielberger, C. D., \& Hansen, P. N. Effects of state anxiety and task difficulty on computer assisted learning. Journal of Educational Psychology, 1969, 60, 343-350.

Spielberger, C. D., Gorsuch, R. L., \& Lushene, P. STAI manual. Palo Alto, Calif: Consulting Psychologists Press, 1970.

Taggart, P., Carruthers, M., \& Somerville, W. Electrocardiogram plasma catecholamines and lipids and their modification by oxprenelol when speaking before an audience. Lancet, 1973, 2, 341-346.

\section{NOTES}

1. The nature and purpose of the study and the risks involved were explained verbally and given on a written form to each subject prior to his voluntary consent to participate. The protocol and procedures for this study have been approved by the Committee on Activities Involving Human Subjects, of the University of California, Santa Barbara.

2. Mylar is a registered trade name of E. I. DuPont de Nemours \& Co., Inc., Wilmington, Delaware.

3. Dilation or constriction may occur in skeletal muscle vasculature, depending on the level of circulating epinephrine. Beta receptors are more sensitive than alpha receptors and dominate at moderate levels of epinephrine output. In contrast, alpha receptors dominate at higher levels of epinephrine, resulting in a net vasoconstriction and a probable rise in TPR (Innes \& Nickerson, 1975).

(Manuscript received June 26, 1981; revision accepted for publication January 19, 1982.) 